\title{
Transitional cell carcinoma of the urinary bladder metastatic to the oral mucosa
}

\author{
KYU SEOB LEE, IK CHAN SONG, HWAN JUNG YUN, DEOG YEON JO, SAMYONG KIM and HYO JIN LEE \\ Division of Hematology/Oncology, Department of Internal Medicine, College of Medicine, \\ Chungnam National University, Daejeon, Republic of Korea
}

Received August 10, 2011; Accepted November 2, 2011

DOI: $10.3892 / \mathrm{ol} .2011 .476$

\begin{abstract}
Metastatic tumors in the oral cavity are rare and usually affect the jaws more often than the oral soft tissues. In particular, metastases confined to the oral mucosa are extremely rare and originate mainly from the lung and breast. Only one case restricted to the oral mucosa and originating from urinary bladder carcinoma has previously been described. We report on a painful polypoid mass located in the oral mucosa with no bone involvement that was confirmed to be a metastatic oral tumor that originated from transitional cell carcinoma of the urinary bladder and progressed rapidly.

\section{Introduction}

Oral metastatic tumors are uncommon, representing approximately $1 \%$ of oral tumors, and usually involve the bones; their occurrence in the oral soft tissues is exceedingly rare. The affected persons usually have widespread disease with a poor prognosis, and the most commonly reported primary sites are the breast, lung, kidney, bone and colon $(1,2)$. Few cases of transitional cell carcinoma of the urinary bladder metastatic to the oral cavity have been reported. Most of these cases occurred in the jawbones, and only three cases occurred in the soft tissues (3). We report on a patient who presented with a metastatic tumor confined to the oral mucosa that originated from a transitional cell carcinoma of the urinary bladder. The patient had widespread disease and a poor prognosis.

The study was approved by the institutional review board, and due to the retropective nature of the study, the requirement to obtain informed consent was waived.
\end{abstract}

Correspondence to: Dr Hyo Jin Lee, Division of Hematology/ Oncology, Department of Internal Medicine, Chungnam National University Hospital, 640 Daesa-dong, Jung-gu, Daejeon, Republic of Korea

E-mail: cymed@cnu.ac.kr

Key words: urinary bladder neoplasm, neoplasm metastasis, mouth neoplasm

\section{Case report}

In December 2004, a 70-year-old man presented with gross hematuria and dysuria. After being diagnosed with transitional cell carcinoma of the urinary bladder following transurethral resection, the patient underwent radical cystectomy (pT3aNOM0, grade 2/3; Fig. 1) and was then followed up regularly. In February 2006, he complained of chest and back pain. Abdominal-pelvic computed tomography (CT) and bone scintigraphy revealed multiple para-aortic lymph nodes and numerous hot spots consistent with bone metastases. These nodes and hots spots were located in the sternum, ribs, thoracolumbar spine, left ilium and left femur. Palliative radiotherapy to the lumbar spine, which was the most painful site, was administered to relieve the pain. The patient then received two cycles of chemotherapy with gemcitabine and carboplatin. In May 2006, the patient presented with a painful polypoid mass, located in the vestibule of the mouth and lateral to the lower right central incisor, which had an irregular surface with a soft consistency and yellowish exudates (Fig. 2). No bone involvement was visible on panoramic or periapical X-rays, bone scintigraphy or CT. A biopsy of the soft tissue mass showed metastatic transitional cell carcinoma of the urinary bladder (Fig. 3). The chest X-ray and CT performed at that time revealed multiple pulmonary metastases. Palliative radiotherapy was planned, but was refused by the patient and his guardians. The patient received supportive care and succumbed to the disease one month after the detection of the oral metastasis.

\section{Discussion}

The case described in this study draws attention to the occurrence of oral mucosal metastasis and the consideration of this phenomenon in the differential diagnosis in urinary bladder cancer patients with an oral mass-like lesion. Metastases to the oral soft tissues, including the oral mucosa, with no bone involvement are exceedingly rare and are most frequently located in the gingiva, followed by the tongue, tonsil, palate, lip, buccal mucosa and floor of the mouth. The most common primary sites of metastatic lesions to the oral mucosa were the breasts in females and lungs in males $(2,4)$. In urinary bladder cancer, metastatic tumors in the oral cavity are uncommon and occur mostly in the jawbones (3). Only three cases of cancer 
Table I. Review of the literature regarding clinical characteristics of oral soft tissue metastasis from urinary bladder cancer.

\begin{tabular}{|c|c|c|c|c|c|c|}
\hline Age & Gender & $\begin{array}{c}\text { Site of soft } \\
\text { tissue metastasis }\end{array}$ & $\begin{array}{c}\text { Other metastatic } \\
\text { lesion(s) }\end{array}$ & Treatment & Survival $^{\mathrm{a}}$ & Ref \\
\hline 62 & $\mathrm{~F}$ & Tongue & None & CTX & 5 months & 5 \\
\hline 75 & M & Submandibular gland & Bone & Surgery & ND & 6 \\
\hline 58 & M & Upper alveolus & $\begin{array}{l}\text { Liver, bone, } \\
\text { adrenal gland }\end{array}$ & None $^{b}$ & ND & 7 \\
\hline
\end{tabular}

${ }^{a}$ Survival duration from the presentation of the oral soft tissue metastasis until death. ${ }^{b}$ Treatment was declined. CTX, chemotherapy; ND, not described; Ref, reference number.

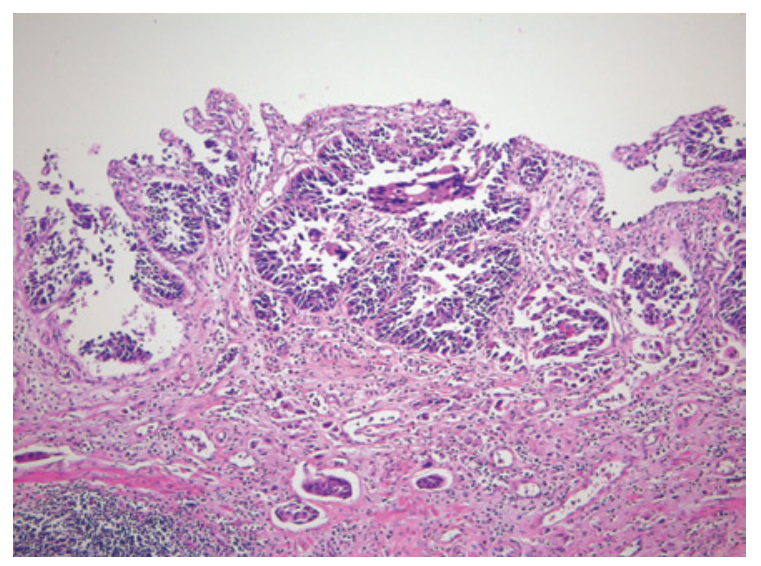

Figure 1. Microscopic examination of the cystectomy specimen reveals papillary transitional cell carcinoma in the bladder epithelium infiltrating the lamina propria (hematoxylin and eosin; original magnification, $\mathrm{x} 100$ ).

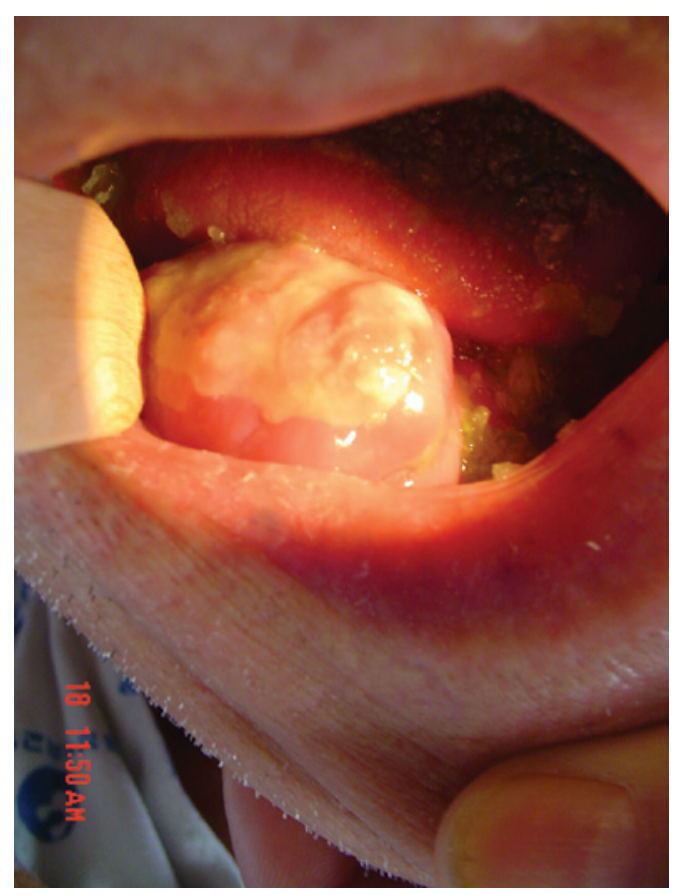

Figure 2. Gross appearance of the metastatic tumor located in the vestibule of the mouth. The polypoid mass reveals an irregular, somewhat lobulated surface with yellowish exudates.

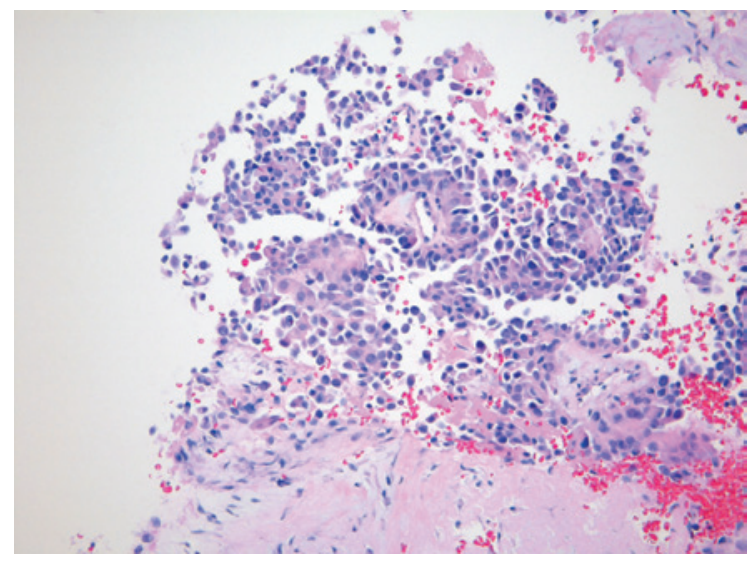

Figure 3. Biopsy specimen of the polypoid mass reveals papillary transitional cell carcinoma (hematoxylin and eosin; original magnification, x200).

confined to the oral soft tissues with no bone involvement have been reported (Table I) (5-7).

The treatment of a metastatic oral lesion depends on the tumor size, location and extent of metastatic lesions, as well as the status of the patient. It is difficult to perform radical treatment for a lesion on a patient in poor general condition, particularly given the low probability of complete removal of the primary and metastatic sites. Conversely, lack of treatment may cause dietary disturbance due to pain and bleeding. Thus, the early removal of the oral lesion may be desirable in terms of quality of life $(2,8)$. In our case, a painful polypoid mass was confined to the oral mucosa with no bone involvement in a patient who had been receiving chemotherapy for recurrent transitional cell carcinoma of the urinary bladder with multiple bone metastases. Initially, the lesion was considered to be a benign gingival one such as an epulis, pyogenic granuloma or peripheral fibroma, since it is extremely rare to encounter transitional cell carcinoma of the urinary bladder metastatic to the oral mucosa without bone involvement. However, a biopsy of the lesion confirmed that it was metastatic transitional carcinoma of the urinary bladder, and the chest X-ray and CT performed at that time revealed multiple pulmonary metastases. The disease progressed rapidly and the patient succumbed within a short period of time, indicating extensive spread of the oral metastatic lesion and a poor prognosis of the disease, as reported in other cases $(9,10)$. 
Clinicians should be aware that a metastatic tumor confined to the oral mucosa is possible, particularly in the advanced stages of cancer, and may provide evidence of widespread disease with a poor prognosis, although such metastatic tumors are exceedingly rare in patients with transitional cell carcinoma of the urinary bladder.

\section{References}

1. Hirshberg A and Buchner A: Metastatic tumours to the oral region. An overview. Eur J Cancer B Oral Oncol 31: 355-360, 1995.

2. Piattelli A, Fioroni $M$ and Rubini C: Gingival metastasis from a medullary thyroid carcinoma: case report. J Periodontol 71 112-116, 2000.

3. De Courten A, Irle C, Samson J and Lombardi T: Metastatic transitional cell carcinoma of the urinary bladder presenting as a mandibular gingival swelling. J Periodontol 72: 688-690, 2001.
4. Hirshberg A, Leibovich P and Buchner A: Metastases to the oral mucosa: analysis of 157 cases. J Oral Pathol Med 22: 385-390, 1993.

5. Koper A, Skinner DG and Calcaterra TC: Carcinoma of the bladder metastatic to the tongue. Br J Urol 47: 644, 1975.

6. Edwab RR, Roberts MJ, Sole MS, Mahoney WD and Rappaport SC: Metastasis of a transitional cell carcinoma of the bladder to the submandibular gland. J Oral Surg 39: 972-974, 1981.

7. Doval DC, Naresh KN, Sabitha KS, Vijaykumar M, Bapsy PP, Anantha N and Kumarswamy SV: Carcinoma of the urinary bladder metastatic to the oral cavity. Indian J Cancer 31: 8-11, 1994.

8. Yoshii T, Muraoka S, Sano N, Furudoi S and Komori T: Large cell carcinoma of the lung metastatic to the mandibular gingiva. J Periodontol 73: 571-574, 2002.

9. Pires FR, Sagarra R, Corrêa ME, Pereira CM, Vargas PA and Lopes MA: Oral metastasis of a hepatocellular carcinoma. Oral Surg Oral Med Oral Pathol Oral Radiol Endod 97: 359-368, 2004

10. Shimoyama S, Seto Y, Aoki F, Ogawa T, Toma T, Endo H, Itouji T and Kaminishi M: Gastric cancer with metastasis to the gingiva. J Gastroenterol Hepatol 19: 831-835, 2004. 